\title{
News from the outgoing President
}

Thave been extremely fortunate to have been surrounded by some exceptional individuals on the Executive and to have been presented with several unique opportunities during my year as President of the Canadian Association of Gastroenterology. As a result, several things have been accomplished.

\section{OFFICIAL JOURNAL}

We have recently adopted The Canadian Journal of Gastroenterology as the Official Journal of our Association. Negotiations with the current Editors-in-Chief, Dr Alan BR Thomson and Dr C Noel Williams, commenced towards the end of 1993 and agreement was reached with them by spring 1994. These negotiations involved myself, the then President-Elect, Dr D Grant Gall, and Vice-President, Dr Joseph Connon. The next series of negotiations was with Pulsus Group Inc, the publishers. The final, legal agreement was signed on September 14, 1994.

As part of the agreement, all official notices, as well as four newsletters per year and the program and abstracts for CAG's Annual Meetings will be published in the Journal.On behalf of the Association, I formally thank and acknowledge Drs Thomson and Williams for their commitment and hard work in establishing and developing the Journal in their capacity as founding Editors-in-Chief. I encourage all members of this Association to support the Journal by submitting high quality, original work for publication.

\section{PERMANENT SECRETARIAT}

This year also saw the establishment of a permanent secretariat for CAG. Our outgoing secretary, Dr Richard Fedorak, has performed outstandingly and has brought a level of organization not seen before by the Association. It was, therefore, the perfect opportunity to establish a permanent secretariat in anticipation of rapid growth and development. Dr Fedorak initiated the selection process and the Executive commissioned Fletcher Wright Associates of Mississauga, Ontario to act as secretariat for the Association. Our liaison, Mr Peter Fletcher, has attended all meetings of the Executive and Governing Board in 1994 and it has been a pleasure to have him as a colleague. Again, the acknowledgement for this achievement should go to Dr Fedorak.

\section{FUNDING}

In the area of funding, we have seen some important new developments. One of these is the establishment of a Research Initiatives Award through Astra Canada. This award provides support for a trainee at the postdoctoral level as well as some overhead for the supervisor's laboratory. The format is such that the contribution is tax deductible under the terms of Bill C22. Acknowledgement for the development of this format should go to Dr Phil Sherman, Chairman of the Research Committee, and $\mathrm{Mr}$ Ray Fynes of Astra Canada. It is hoped that this new format will be attractive to others in industry and that it will facilitate more funding of research in gastroenterology and education of our trainees in research in the future. I would also like to acknowledge the support of Janssen Pharmaceutica, Glaxo Canada and Eli Lilly for providing fellowships in gastroenterology.

For the first time CAG will be able to offer a fellowship in endoscopy. This is the result of the unselfish work of Dr Malcolm Champion, Chairman of the Finance Committee, who negotiated with Carsen Group Inc. The Association congratulates him on his initiative. Details of this award will be available shortly.

\section{MOTILITY FELLOWSHIP}

This year has seen another innovative development between the Association and industry. Janssen Pharmaceutica approached CAG with the prospect of generously funding two Centres for Excellence in GI Motility Education. The proposal was made public in New Orleans in May and Dr Micheline Ste Marie was asked to form a small committee to evaluate the idea and develop it into a tangible prospect. With the assistance of Keith Sharkey and Bill Paterson, she was able to develop a proposal in time for distribution during the summer. The application is open to all academic institutions in Canada. The successful institutions will be expected to maintain a state-of-the-art profile in the provision of service and research in motility and to use this to generate educational events for residents, interns and subspecialists. This is an innovative idea, the credit for which must go to Janssen for its conceptualization and to Micheline and her committee for its execution. A panel consisting of national and 
international experts will review the applications in November and a decision is expected by the end of 1994.

\section{CANADIAN DIGESTIVE DISEASES WEEK}

Finally, I am most excited to report the Association's decision to establish a Canadian Digestive Diseases Week. I established a task force under the chairmanship of Dr Alan Thomson to investigate the feasibility of a CDDW. That committee concluded that a CDDW was not only feasible but essential if the Association is to respond appropriately to the diverse needs of its membership. These include the needs of GI residents, educators and researchers in academic gastroenterology, and gastroenterologists in practice. There is no doubt that the formulation of the idea of a CDDW was catalyzed by the success and popularity of the annual postgraduate course for GI residents pioneered by Dr Gary Levy and Dr Thomson. It is important to preserve the identity and unique characteristics of this course within the proposed CDDW.

The needs of practising gastroenterologists are constantly changing, particularly in light of the uncertainty surrounding the future of health care across provinces. In response to this, my predecessor, Dr Richard Hunt, established an ad hoc Practice Affairs Committee chaired by Dr Ron Tanton. Such is the importance of this sector of activity that the Executive has proposed that the
Committee become a Standing Committee over the next year. It is expected that the Practice Affairs Committee will play an important role, not only in addressing the challenges facing our subspecialty by government, but also in using the CDDW as a forum at which to discuss these issues with the membership at large, and to provide the continuing medical education needs of practising members of CAG. We will not forget our longstanding association with the Royal College and the Canadian Society for Clinical Investigation. We propose to continue our presence at Royal College annual meetings but to contribute in a manner that will enhance collaborations with other societies within the College and CSCI.

I believe that the Association has moved to a new level over the past few years and I feel grateful and honoured to have had an opportunity to make my contributions to this transition. I was fortunate enough to be presented with some unique opportunities and to be surrounded by very capable individuals with whom I could share the load and responsibility. It is with a feeling of both satisfaction and much anticipation that I now pass the Presidency on to my friend and colleague Dr Grant Gall.

Steven M Collins MBBS FRCP(UK) FRCPC President (1993-94), Canadian Association of Gastroenterology Hamilton, Ontario 


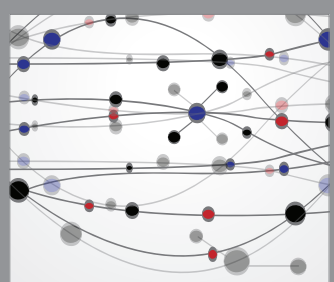

The Scientific World Journal
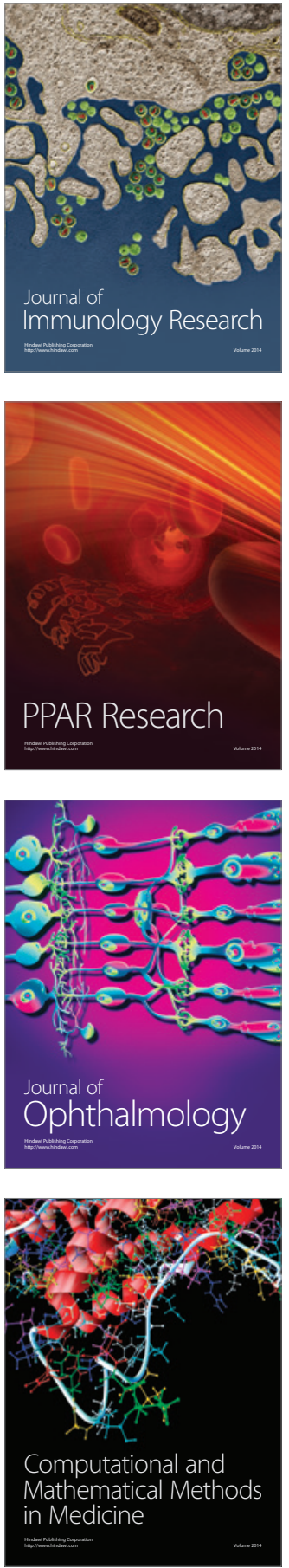

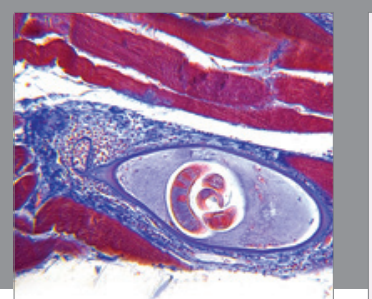

Gastroenterology Research and Practice

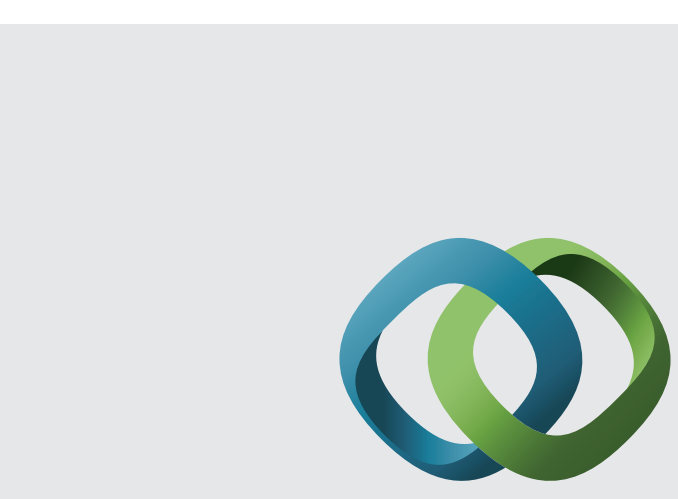

\section{Hindawi}

Submit your manuscripts at

http://www.hindawi.com
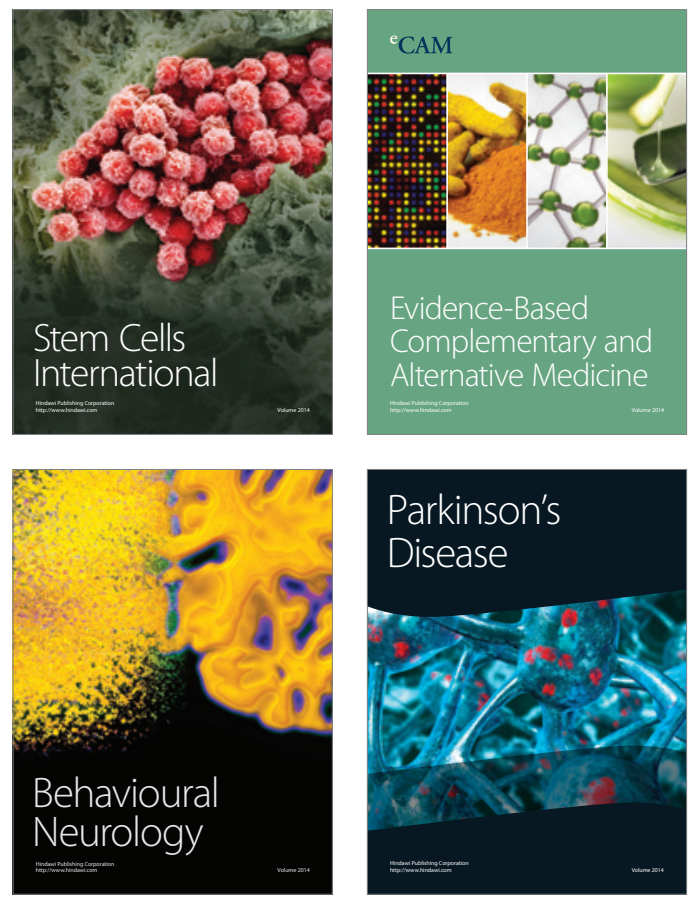
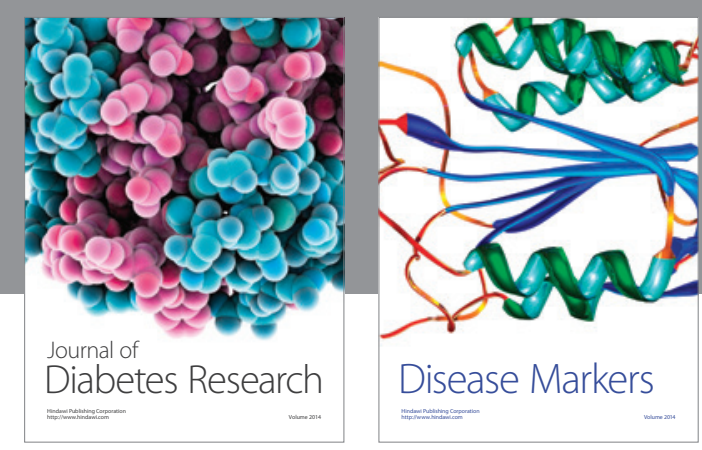

Disease Markers
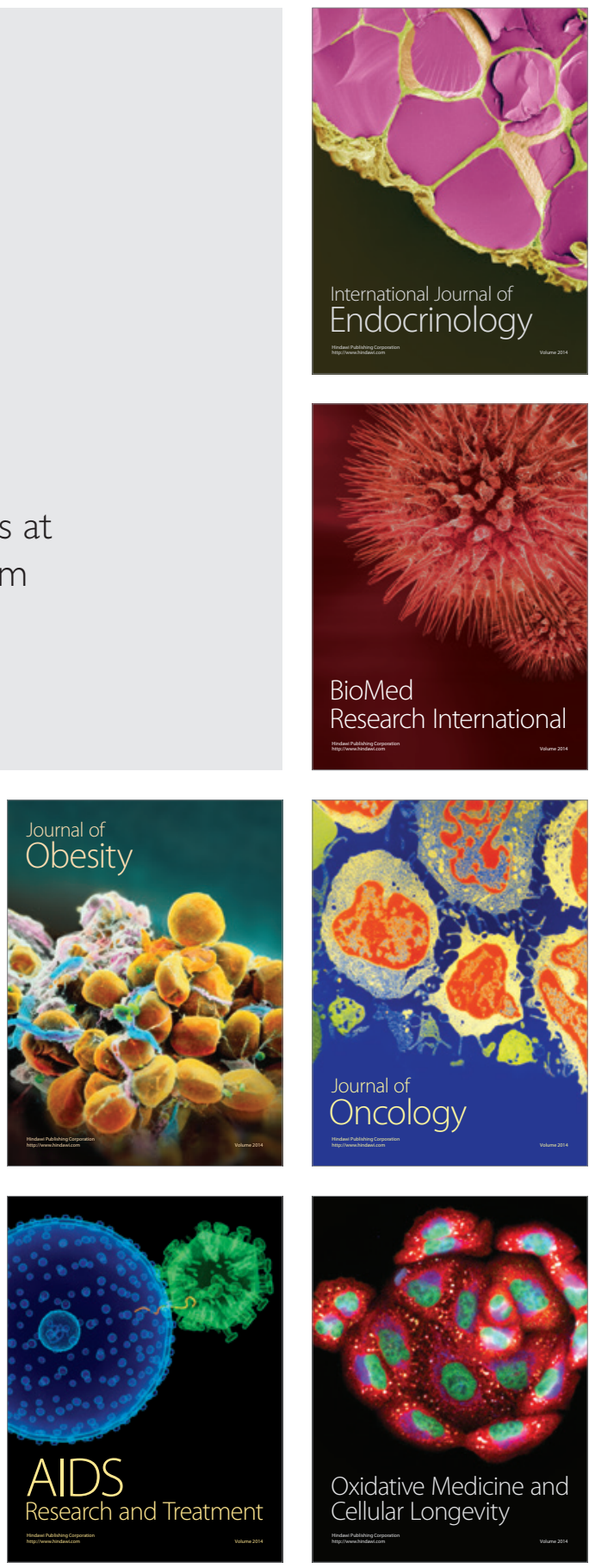